\title{
Tensile behaviour of Inconel 718 alloys under extreme con- ditions of temperature and strain-rate
}

\author{
Ezio Cadoni ${ }^{1, *}$, Daniele Forni ${ }^{1}$, Federico Mazzucato $^{2}$, and Anna Valente $^{2}$ \\ ${ }^{1}$ DynaMat SUPSI Laboratory, University of Applied Sciences and Arts of Southern Switzerland, Via \\ Catenazzi 23, 6850 Mendrisio, Switzerland. \\ ${ }^{2}$ Automation Robotics and Machines Laboratory, University of Applied Sciences and Arts of Southern \\ Switzerland, Via la Santa 1, 6962 Lugano-Viganello, Switzerland.
}

\begin{abstract}
Nickel-based superalloys are widely used in critical applications where structural components are subjected to harsh operating conditions such as elevated temperatures and high strain-rate. These alloys are also among the most hard-to-cut materials. For this reason, some critical components with complex geometrical features along with critical dimensions cannot easily manufactured by conventional technologies. A rising disruptive Additive Manufacturing (AM) technique, namely powder-based Laser Metal Deposition (LMD), is able to overcome these limitations in terms of manufacturing costs, tool wear, as well as lead time. As a consequence, the mechanical response under harsh condition of additively manufactured Nickel-based superalloys has to be accurately understood in order to guarantee the reliability of the structural parts made with them. Presently very few researches were addressed to study the dynamic tensile behaviour of Inconel 718 produced by additive manufacturing under high strain-rate combined with elevated temperature. To overcome this lack, the coupled effect of strain rate $\left(0.001 \mathrm{~s}^{-1}, 250 \mathrm{~s}^{-1}\right.$ and $\left.800 \mathrm{~s}^{-1}\right)$ and temperature $\left(20^{\circ} \mathrm{C}, 350^{\circ} \mathrm{C}\right.$ and $\left.550^{\circ} \mathrm{C}\right)$ on the tensile properties of Inconel 718 alloys produced through cast and additive manufacturing technologies has been experimentally studied. The experiments were also addressed to investigate and compare the flow stress behaviour in function of strain rate and temperature considering the differences in terms of microstructure. A modest strain-rate sensitivity has been observed for both as-cast and as-built material, as well as a moderate decrease of the mechanical strengths has been highlighted for increasing temperatures. Finally, comparable mechanical behaviour has been observed between additively manufactured samples produced with a power laser of $400 \mathrm{~W}$ and as-cast samples.
\end{abstract}

\section{Introduction}

Thanks to their excellent mechanical properties at elevated temperatures, good wear and corrosion resistance Nickel-based superalloys are widely used in critical applications where structural components are subjected to complex and harsh environmental conditions both in terms of temperature and strain-rate [1]. Although Inconel 718 has good formability and weldability, this alloy is commonly considered one of the most hard-to-cut materials due to its

\footnotetext{
*e-mail: ezio.cadoni@supsi.ch
} 
own properties (i.e. poor thermal diffusivity, high strength at elevated temperature, etc.). Critical components presenting complex geometrical features along with critical dimensions cannot currently be manufactured by conventional technologies. Additive manufacturing technology enables the targeting of complex shape components presenting cutting-edge dynamic behaviour, i.e. where impulsive loadings with high strain-rates together with severe conditions of temperature cannot result in catastrophic failure. Consequently, dynamic mechanical response of the Inconel 718 alloys has to be accurately understood in order to guarantee the reliability of the structural parts made with them.

In Additive Manufacturing (AM), the process known as Laser Metal Deposition (LMD) relies upon a mixture of carrier gas and metal powder particles that are blown out from a set of nozzles. The particles are projected toward the target deposition spot, where a laser beam fuses them along with the underlying substrate, forming a melt pool, i.e. a drop of molten metal. As the deposition head moves, the melt pool cools down, evolving into a solid metal track of the desired geometry. LMD is the AM technology with the largest potential to improve the manufacturing of metal components, thanks to its capability to limit the material waste, to manufacture parts with high geometrical and topological complexities, to restore damaged parts and to add coatings.

One of the sectors which would be most interested in using LMD at industrial level is aerospace, where the manufacturing of high-performance, complex geometry spare parts is nowadays not cost-effective.

Presently, very few researches were addressed to study the dynamic tensile behaviour of Inconel 718 produced by additive manufacturing under high strain-rate combined with elevated temperature [2].

In this paper the strain rate effect on the tensile properties of Inconel 718 alloys, produced through cast and additive manufacturing, has been experimentally studied. Two different temperatures $\left(350^{\circ} \mathrm{C}\right.$ and $\left.550^{\circ} \mathrm{C}\right)$ were selected according to the operative need of structural components, in combination of two strain-rates $\left(250 \mathrm{~s}^{-1}\right.$ and $\left.800 \mathrm{~s}^{-1}\right)$. In addition, quasistatic tests and high strain rate tests were performed at room temperature as well. The strainrates imposed at room temperature were also used for the elevated temperature tests. The experiments were also addressed to investigate and compare the flow stress behaviour in function of strain rate and temperature considering the differences in terms of microstructure.

\section{Materials}

The achievement of specific product quality Key Performance Indicators (KPIs) such as porosity percentage, absence of cracks, superficial roughness and dimensional fitting demands the design of a comprehensive testing campaign where several process recipes (laser power, carrier-powder mix and axes feed) are run on the same manufacturing infrastructure [3]. The samples are designed with increased geometrical, dimensional and functional complexity - from single tracks to tensile samples and bulky net shape components. Once manufactured, the very same samples undergo destructive and non-destructive tests in order to assess the KPIs and to select the best process recipe. Also, the tensile samples are evaluated with regard to conventional technologies (such as casting).

\subsection{Preparation of materials}

Three materials were studied in this research. Two of these - namely as-built materials - are based on an Inconel 718 gas atomised powder (powder particle size ranging between $44 \mu \mathrm{m}$ and $106 \mu \mathrm{m}$ ) and were prepared using a powder-based Laser Metal Deposition technique 

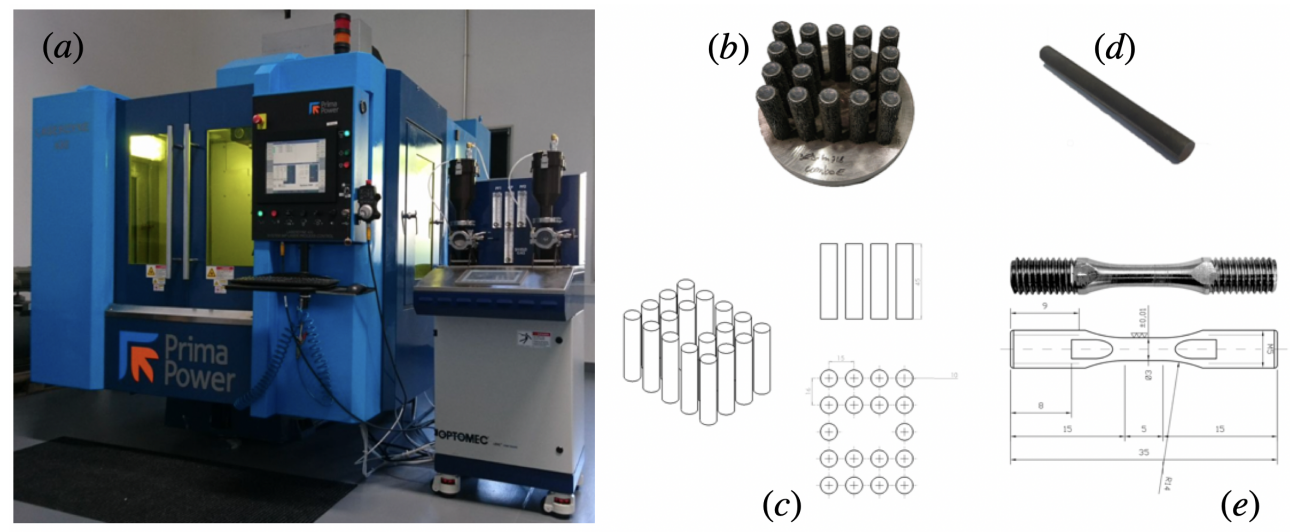

$(e)$

Figure 1: Laserdyne 430 laser cutting machine $(a)$, additively manufactured cylinders $(b$ and $c)$, single cylinder after EDM trimming $(a)$ and final as-built sample geometry after diamond grinding and turning $(e)$.

Table 1: Inconel 718 alloys studied in this research. Data from [2]

\begin{tabular}{lccccc}
\hline $\begin{array}{l}\text { Material } \\
\text { name }\end{array}$ & $\begin{array}{c}\text { Laser } \\
\text { power } \\
{[\mathrm{W}]}\end{array}$ & $\begin{array}{c}\text { Axis } \\
\text { speed } \\
{[\mathrm{mm} / \mathrm{min}]}\end{array}$ & $\begin{array}{c}\text { Hatching } \\
\text { distance } \\
{[\mathrm{mm}]}\end{array}$ & $\begin{array}{c}\text { Feed } \\
\text { rate } \\
{[\mathrm{g} / \mathrm{s}]}\end{array}$ & $\begin{array}{c}\text { Layer } \\
\text { thickness } \\
{[\mathrm{mm}]}\end{array}$ \\
\hline \hline As-built P300W Inconel 718 & 300 & 750 & 0.384 & 0.032 & 0.151 \\
As-built P400W Inconel 718 & 400 & 750 & 0.414 & 0.032 & 0.208 \\
As-cast Inconel 718 & n.a. & n.a. & n.a. & n.a. & n.a. \\
\hline
\end{tabular}

belonging to the family of DED technologies as defined in ISO/ASTM 52900:2015 [4]. A full description of the preparation of as-built materials (Figure 1) is reported in Mazzucato et al. [3] as well as the combinations of process parameters (laser power, axis speed, hatching distance, feed rate and layer thickness) adopted for the manufacturing (Table 1). The third material - namely as-cast material - is a commercial Inconel 718 and was used as raw material for the preparation of as-cast samples (Table 1).

\section{Experimental procedure}

Experiments were carried out on round samples with $3 \mathrm{~mm}$ in diameter and $5 \mathrm{~mm}$ of gauge length (Figure 1e) by means of a Split Hopkinson Tensile Bar equipped with an Ambrell compact EASYHEAT induction water-cooled heating system with maximum power of 2.4 $\mathrm{kW}$ (Figure 2). It is worth pointing out that, in order to check the temperature gradient in both bars (e.g. see the output bar in Figure 2), five thermocouples were welded in 5 different positions between the sample and the cooling system (sample and at $10 \mathrm{~mm}, 30 \mathrm{~mm}, 50 \mathrm{~mm}$ and $80 \mathrm{~mm}$ from the sample). In the worst position (e.g. thermocouple at $10 \mathrm{~mm}$ from the sample) the temperature increment in the bar was approximately of $240^{\circ} \mathrm{C}$ (test at $550^{\circ} \mathrm{C}$ ) and $150^{\circ} \mathrm{C}$ (test at $350^{\circ} \mathrm{C}$ ). On the other hand, at $80 \mathrm{~mm}$ from the sample, the temperature increment in the bar was negligible (less than $100^{\circ} \mathrm{C}$ ).

A detailed description about the preparation of samples is reported in $[2,3]$, while an exhaustive description of the SHTB equipped with the heating systems, as well as the basic 


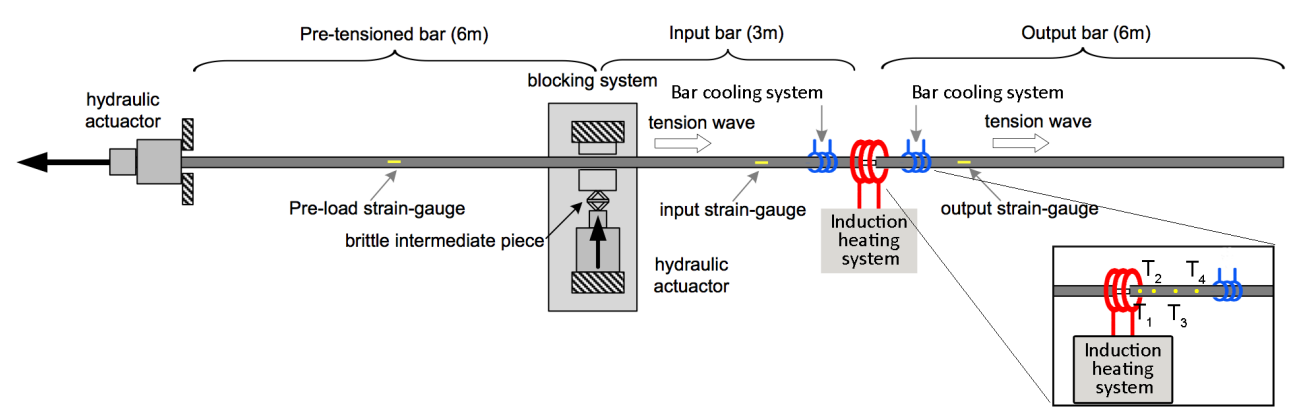

Figure 2: Scheme the Modified Hopkinson bar equipped with the induction heating system.

assumptions to be fulfilled in order to obtain an accurate measurement of the mechanical properties of a material under dynamic loading have been reported in $[5,6]$.

\section{Results and discussion}

With the intention of comparing tests at different temperatures with comparable strain-rates, the testing conditions adopted at room temperature were adapted for tests at elevated temperatures by compensating the preload in the pretensioned bar. From Figure 3 it is possible to observe how the strain-rate flow is nearly the same for tests at different temperatures. From Figure 3 it is also possible to observe how at high strain-rate (e.g. $\left.800 \mathrm{~s}^{-1}\right)$ the fracture strain decreases for increasing temperatures.

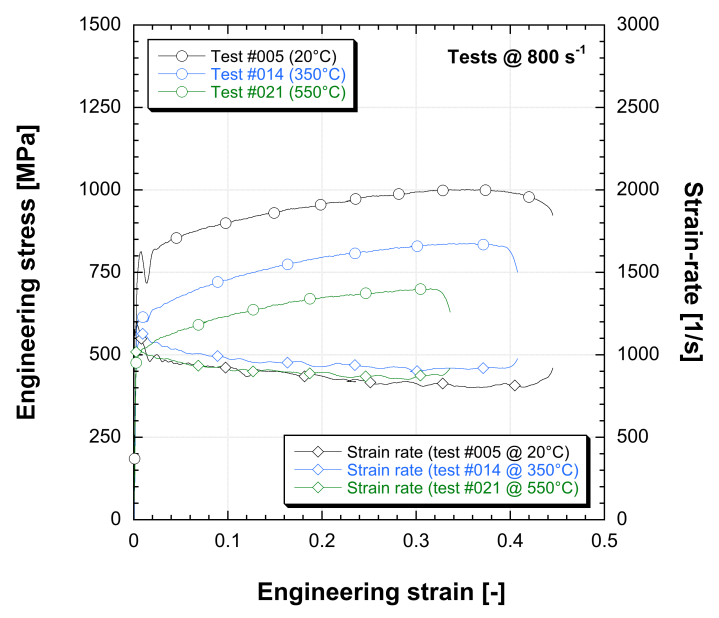

Figure 3: Engineering stress and strain-rate versus time. Representative data for as-cast tests performed at $800 \mathrm{~s}^{-1}$.

From the experimental results at room temperature, both the as-cast and the as-built materials have highlighted a modest strain-rate sensitivity. However, the as-built material realised with a power laser of $400 \mathrm{~W}$ highlight an higher strain-rate sensitivity than the as-built material realised with a power laser of $300 \mathrm{~W}$ (Figure 4). It is worth noting that at room temperature a 
similar mechanical behaviour in terms of uniform strain and ultimate tensile strength has been highlighted between the as-cast material and the as-built material realised with a power laser of $400 \mathrm{~W}$. In addition, at room temperature a better flow stress repeatability has been noted for the as-built material produced with a laser power of $300 \mathrm{~W}$ (Figure 5a). Furthermore, the flow stress repeatability rises at elevated temperatures (Figure 5). Finally, from the experimental results comparison at elevated temperatures the thermal softening effect has been highlighted. Moreover, high strain-rate test results at $550^{\circ} \mathrm{C}$ highlighted a similar mechanical behaviour in terms of flow stress for both as-cast and as-built materials.

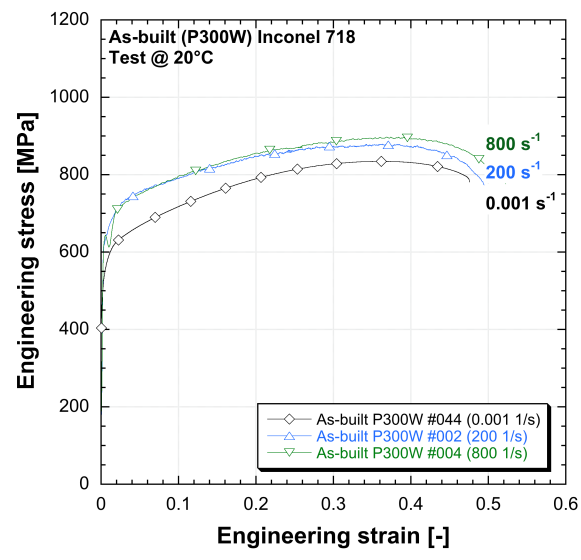

(a) As-built (P300W) Inconel 718

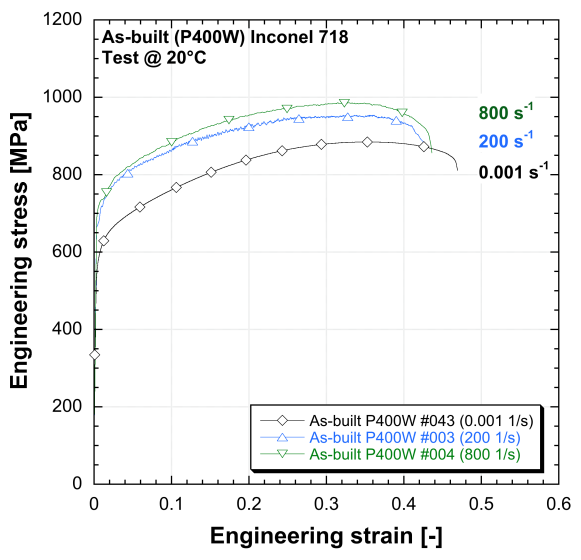

(b) As-built (P400W) Inconel 718

Figure 4: Engineering flow stress for both as-built materials.

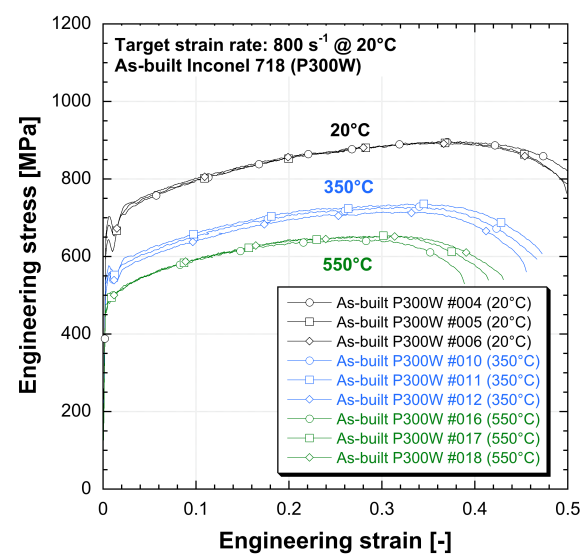

(a) As-built (P300W) Inconel 718

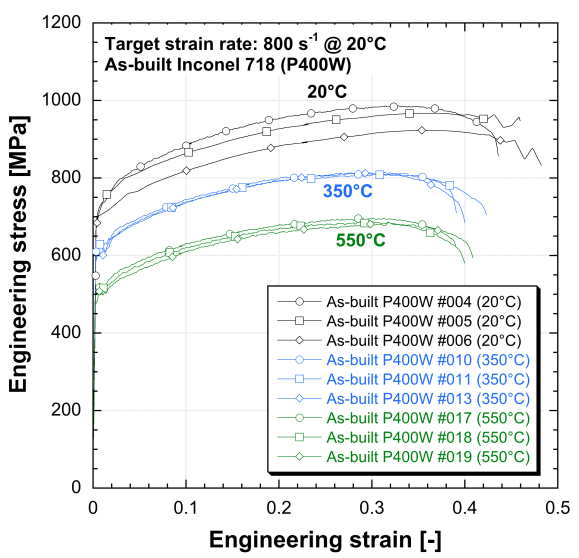

(b) As-built (P400W) Inconel 718

Figure 5: Engineering flow stresses for both as-built materials at the same target strain-rate and different temperatures. 


\section{Conclusions}

In this paper, the mechanical properties under severe combined conditions of temperature and strain-rates of a raw Inconel 718 material and two as built Inconel 718 materials were studied and compared. A split Hopkinson tensile bar equipped with a water-cooled induction heating system was used. The as-built materials were prepared by using a Laser Metal Deposition (LMD) system. On the basis of the experimental results, the following conclusions can be drawn:

- The as-built materials produced with a laser power of $300 \mathrm{~W}$ and $400 \mathrm{~W}$ highlighted a modest strain-rate sensitivity. Moreover, both materials kept their strain hardening capacities under harsh combined conditions of high strain-rates and temperatures.

- The as-cast Inconel 718 material kept its strain hardening capacities under the same severe conditions as well.

- An improvement in terms of mechanical behaviour repeatability was noted at elevated temperatures.

- At room temperature the mechanical behaviour of the as-built Inconel 718 material produced with a power laser of $400 \mathrm{~W}$ was similar to mechanical behaviour of the as-cast material.

- At high strain rates and at elevated temperature the as-cast material and the as-built materials showed a comparable mechanical behaviour.

\section{References}

[1] J. Johansson, C. Persson, G. Testa, A. Ruggiero, N. Bonora, M. Hörnqvist Colliander, Mech. Mater. 109, 88-100 (2017)

[2] D. Forni, F. Mazzucato, A. Valente, E. Cadoni, Mech. Mater. https://doi.org/10.1016/j.mechmat.2021.103859, (2021)

[3] F. Mazzucato, D. Forni, A. Valente, E. Cadoni, Materials 2, 1-21 (2021)

[4] ISO/ASTM 52900:2015, Additive manufacturing - General principles - Terminology

[5] D. Forni, B. Chiaia, E. Cadoni, Mat. Des. 94, 467-478 (2016)

[6] E. Cadoni and D. Forni, Fire Safety J., 109, 102869 (2019) 